\title{
Behaviors of Reinforced Concrete Slab Voided by Circular Paper Tubes
}

\author{
Mamush Teklie ${ }^{1, *}$, Tesfaye Alemu ${ }^{1}$, Beka Benti \\ ${ }^{1}$ Department of Civil Engineering, College of Architecture and Civil Engineering, Addis Ababa Science and Technology University, Addis \\ Ababa, Ethiopia \\ ${ }^{2}$ Department of Water Resources Engineering, School of Civil Engineering and Architecture, Adama Science and Technology University, \\ Adama, Ethiopia
}

Email address:

mamusht72@gmail.com (M. Teklie)

${ }^{*}$ Corresponding author

\section{To cite this article:}

Mamush Teklie, Tesfaye Alemu, Beka Benti. Behaviors of Reinforced Concrete Slab Voided by Circular Paper Tubes. Engineering Science. Vol. 5, No. 4, 2020, pp. 45-56. doi: 10.11648/j.es.20200504.11

Received: October 1, 2020; Accepted: November 2, 2020; Published: December 11, 2020

\begin{abstract}
Voided slab construction is a way of effectively removing concrete from middle section of a RC slab which has not a structural function, thereby reducing structural dead weight. Voided slab construction has advantages such as reducing self-weight, Cost efficiencies and fast Construction. However, floor stiffness of voided RC slab is less than its solid counterpart and there is gap in literature about structural behaviors of voided RC slabs. This research work presents experimental and numerical investigations of voided RC slab. Six solid and voided RC slab specimens of size $800 \mathrm{~mm} 300 \mathrm{~mm} \times 200 \mathrm{~mm}$ were casted and tested until failure under one-point load. Also, leveraging advantages of FEA, effect of influential variables such as void size, loading type, concrete compressive strength, and effect of top reinforcement were thoroughly studied. Experimental test results indicated as compared to control solid RC slab, $60 \mathrm{~mm}$ diameter paper tube voided RC slab exhibited $12 \%$, $15.54 \%$, $25.50 \%, 14.64 \%$ and $6.71 \%$ loss in strength, cracking load, stiffness, ductility, and toughness respectively where as for $90 \mathrm{~mm}$ diameter paper tube voided RC slab respective values were 20\%, 19.87\%, 38.80\%, 25.50\% and 12\%. Also, as void size increased from $60 \mathrm{~mm}$ to $90 \mathrm{~mm}$, voided slab failure mode changed from flexural to shear. Finally, FEA, ACI $318 \mathrm{M}-19$ and EC2 codes showed good agreement with experimental results.
\end{abstract}

Keywords: Voided RC Slab, Ductility, Floor Stiffness, Finite Element Analysis

\section{Introduction}

\subsection{General}

A slab is a very important structural element in building construction and it uses to offer flat surface to a structure and distribute loads to the supported beams and columns. Since it consumes more concrete and steel reinforcement, the selfweight of the slab is increasing. To overcome these disadvantages, voided slab plate is the best structural option since the load transfers from the slab structure only on the column portion not throughout the slab.

Voided slab is a RC slab with an internal void former that replace the concrete between the lower and the upper reinforcement.
This system allows to reduce the self-weight, which have special benefit for foundations with low bearing capacity of soil, and induces materials and cost savings, as fire resistance and for electrical and mechanical purposes. To share such advantages, the implementation of the voided slab must be addressed.

\subsection{Statement of the Problem}

A longitudinal tube voids through the one-way RC slabs in constructions has been several advantages such as reducing self-weight, Cost efficiencies and fast Construction.

In other hand, the structural behaviors of one-way RC slab need special treatment during design, since the loads is carried in one direction and any errors in design results in early failure of slabs. The presence of voids in this direction 
could raise this problem.

Therefore, this research work fills in perceived void in literature by investigating structural behaviors of one-way $\mathrm{RC}$ slabs voided by different tube size to investigate the effects of void size to slab thickness ratio compare with solid RC slab. In addition to these, after the validation of the FEA solution was checked, the effect of some additional parameters on the behavior of slabs were studied using finite element software ANSYS. Finally, the flexure strength and load carrying capacity of the tested slabs were determined as per the EC2 and ACI 318M-19 codes.

\subsection{General Objective}

Objective of this research work is to investigate structural behaviors of RC slab voided by circular paper tubes.

\subsection{Specific Objective}

1. To study use of longitudinal circular paper tube as partial concrete replacement in RC slab.

2. To quantify structural gains or loss of RC slabs voided by different tube diameter to slab thickness ratio as compared to solid RC slab.

3. To show the effects of some additional parameters on the behavior of slabs (not in test studies) by using nonlinear finite element software ANSYS, after the validation of the finite element solution is checked.

4. To study ultimate failure load and failure modes of RC slabs voided by different tube size as compared to solid RC slab.

5. To determine the flexure strengths of the slabs as per the ACI 318M-19 and EC2 codes using theoretical hand Calculation.

\subsection{Significance of the Study}

Researchers and practitioners can potentially benefit from the output of this research work. Such as:

1. It will increase awareness of practicing the Voided Technology, the RC slabs with longitudinal paper tube system, is the most effective solution to concrete structures against extreme loading such as earthquake, impact and blast loading.

2. To gain an understanding relative to weight reduction, behaviors, capacity and cost benefit of RC slabs voided by longitudinal hollow system.

3. Faster construction time, Less Material Consumption, Less Energy consumption as a result the total cost of the building become reduced.

4. To develop constructions as flexible and generally applicable and to pick up changes in a time period reaching far into the next century our country.

\section{Literature Review}

\subsection{General}

A voided slab is a cast-in-situ or precast reinforced concrete slab usually used in building floors, bridges, etc. The acceptance of reinforced concrete voided slab is related with seismic areas, cost efficiencies and fast construction, reduce self-weight, and consumes less materials. The lower weight is very important issue because it reduced the costs of transportation and construction costs. The slab with continuous holes is being as heating and/or cooling ducts and as channels for electrical wiring. In addition, sound transmission and vibrations among building floors can be minimized using voided slabs. [15]

\subsection{Existing Studies on Hollow Core Slab}

Pre-stressed hollow core slabs tested specimen showed substantial ductility after failure and the tested specimens under this condition didn't collapse but the test had to be stopped due to the extreme rotation. [2] The behavior of hollow reinforced and pre-stressed slabs against some changes in the model and material parameters was able through parametric studies when the load-deflection response is obtained. These parameters contained within the influence of concrete strength, pre-stressing tendon amount, existence of holes, hole size, hole shape and failure concrete crushing strain. Generally, the acceptable level of matching between the results obtained from finite element and the investigational work. [3]

The web shear capacity of hollow core slabs (HCS) through a large number of shear tests. The analysis of results indicated that the minimum shear reinforcement requirement for deep HCS members are too severe, and that the webshear strength equation in ACI 318 code does not provide good estimation of shear strengths for HCS members. Thus, a rational web-shear strength equation for HCS members was derived in a simple manner, which provides a consistent margin of safety on shear strength for the HCS members up to $500 \mathrm{~mm}$ deep. $[1,6]$ The research found that the horizontal shear is not what governs the strength and response of slabs. The Euro code 2 does not give an estimate for shear strength, whilst the previous researcher equation was able to provide that. [7]

A study that includes both numerical research and investigational work regarding the shear strength of concrete slabs with longitudinal hollow cores. The studied specimen had different hollow cores dimensions and were examined under different load conditions by varying the distances of ratios $(a / b)$. The dimensions of the tested specimens were $(2.05 \mathrm{~m})$ in length, $(0.6 \mathrm{~m})$ in width and $(0.25 \mathrm{~m})$ thickness. Results obtained from testing showed a $21 \%$ to $33 \%$ reduction in the ultimate strength of solids and $13 \%$ to $48.5 \%$ reduction in deflection in the center of the slabs relative to the increase in the shear span ratio from 2 to 2.5 and 3 respectively. In addition, a reduction in the ultimate strength by $(5.49 \%, 15.75$ and $20.6 \%$ ) was found due to the existence of the circular hollow cores with a diameter of $(75,100$ and $150 \mathrm{~mm})$. Finally, the load of HCS was reduced by nearly $31 \%$ to $45 \%$, at the same time an increase in the deflection by $24.8 \%$ and $68.5 \%$ was noticed respectively. [8] A full-scale precast pre-stressed hollow- 
core slabs (PPHC), using various (a/d) can be determine failure load of slabs. For a depth greater than $200 \mathrm{~mm}$ the results were interesting such the failure type of HCS has varied from pure bending to bending-shear mode. Furthermore, the shear strength of (PPHC) slabs has reduced with the increment in depth. [4] The value of the flexural stiffness of the solid slab is greater than HCS. A crack that occurs in the solid slab is distinguished as flexural crack, although the cracks which occur in the HCS is shear cracks. [9, 10] The bending performance of a precast reinforced concrete floor or slab having steel fibers concrete topping varies in behaviors of toughness due to the interaction between the new and old concrete. To study the composite samples, the interface bond slip was also calculated during the experiment. The result shown that roughness of the transverse direction offers the good bonding interface strength. [14]

\subsection{Research Gaps}

The previous researcher assessed the effects of voids on one-way RC voided slab based on deflections and ultimate strength at the failure stage or/and service stage. However, the effects of the parametric study (void tube diameter to slab thickness ratio with varying in size of tube) on the behaviors of the slab structure has not been adequately inspected well, especially for one-way slabs. Besides, the basic structural behaviors like floor stiffness, ductility ratio and toughness have not been comprehensively examined in the past studies.
This thesis, after the validation of the FEA solution was checked, the effect of some additional parameters such as concrete compressive strength, loading types, top layer reinforcement on the behavior of slabs have been studied using finite element software ANSYS. Finally, the flexure strengths and load carrying capacity of the slabs were also determined per the ACI $318 \mathrm{M}-19$ and EC2 codes. [11-13]

\section{Methodology}

\subsection{Details of Experimental Test}

The experimental tests were consisting of six simply supported reinforced concrete one-way slab. All slab specimens have dimensions of $(800 \mathrm{~mm})$ length, $(300 \mathrm{~mm})$ width and, $(200 \mathrm{~mm})$ thickness with two different size of circular tubes and without tubes were used. To make the continuous longitudinal hollows within the slabs, paper tubes are used. Two diameters of $90 \mathrm{~mm}$ and $60 \mathrm{~mm}$ size are used. The tube voids were fixed in their positions using binding wires. In the name of the specimen, the symbol indicates the presence or absence of voids ( $\mathrm{SS}=\mathrm{RC}$ solid slab and $\mathrm{CPT}=\mathrm{RC}$ with circular paper tube slab). SS200 is a normal $\mathrm{RC}$ slab; CPT60 and CPT90 are RC voided slabs with circular paper tube of diameter $60 \mathrm{~mm}$ and $90 \mathrm{~mm}$ respectively. The comparative specimens for SS200, CPT60 and CPT90 slab were with the same slab thickness, except that circular paper tubes were applied to CPT60 and CPT90.

Table 1. Details of specimens.

\begin{tabular}{llll}
\hline Slab type & Specimens code & No of specimens & D/H Ratio \\
\hline Solid Slab & SS200 & 2 & \\
Voided-tube $(60 \mathrm{~mm})$ & CPT60 & 2 & $30 \%$ \\
Voided-tube $(90 \mathrm{~mm})$ & CPT90 & 2 & $45 \%$ \\
\hline
\end{tabular}

Table 2. Material Properties.

\begin{tabular}{lll}
\hline 1. Compressive strength of concrete cube test & & \\
\hline Specimens type & cube test (15x15x15cm) & Age 28days (MPa) \\
\hline & Age 7days (MPa) & 44.60 \\
\hline SS200 & 27.19 & 44.50 \\
CPT60 & 27.06 & 44.50 \\
CPT90 & 27.48 & 44.50 \\
Average at the end of 28 days & & \\
\hline
\end{tabular}

\begin{tabular}{llll}
\hline 2. Properties of steel reinforcement & & & \\
\hline Material & size & Yield strength (MPa) & Ultimate strength (MPa) \\
\hline Reinforcement & $\varnothing 10 \mathrm{bar}$ & 535 & 697 \\
& $\varnothing 6 \mathrm{bar}$ & 305 & 460 \\
\hline
\end{tabular}

The position of the bottom and top flange of concrete was fixed $70 \mathrm{~mm}$ and $55 \mathrm{~mm}$ for tube void diameter of $60 \mathrm{~mm}$ and $90 \mathrm{~mm}$ respectively. The tubes were distributed with the same spacing inside the slabs by two tubes in the longitudinal direction. The spacing between tubes was $60 \mathrm{~mm}$ for both CPT60 and CPT90 specimens. Objective of this research work is to investigate structural behaviors of longitudinally voided one-way RC slab and to assess the effects of void size to slab thickness $(\mathrm{D} / \mathrm{H})$ ratio on the structural performance comparable with solid RC slab. Details of specimens are listed in Table 1.

\subsection{Properties of the Slab Specimens}

The reinforcement design for one- way slab was done based on the design procedure given in ACI318-2014 for both solid slab and voided-tube slabs. The main longitudinal reinforcement consists of 4 bars with $(\varnothing 10 \mathrm{~mm})$ at top and at bottom with center to center spacing $80 \mathrm{~mm}$ while the 
secondary transverse reinforcement consists of 6 bars $(\varnothing 10 \mathrm{~mm})$ at top and bottom with center to center spacing $150 \mathrm{~mm}$. The concrete cover of reinforcing bars for all sides was $25 \mathrm{~mm}$ as given in Figure 1.

To estimate the properties of concrete, cubes with dimensions of $150 \times 150 \times 150 \mathrm{~mm}$ were made for each series of specimens. The Compressive strength of concrete cubes was evaluated after 7 days and 28 days curing. An average of 3 cubes for each test was used to estimate the compressive strength and the cube concrete grade result was 44.50MPa. The experimental results of concrete Compressive strength and properties of reinforcing bars presented in Table 2.

\subsection{Testing of the Slab Specimens}

The nominal dimension slab specimens are models having $(800 \mathrm{~mm})$ length, $(300 \mathrm{~mm})$ width and $(200 \mathrm{~mm})$ thickness. The slabs which have span length $650 \mathrm{~mm}$ (center to center of supports) were tested under single line loads with different void diameter to slab thickness ratio $(\mathrm{D} / \mathrm{H})$ in $\mathrm{EiABC}$ University, Ethiopia, on January 2020.

The slab to be tested was placed in the loading frame of capacity $2000 \mathrm{kN}$ under one-point loading and preparation of the test specimen during experimentation work are illustrated in Figure 1 (d). A steel plate with $(50 \times 300 \mathrm{~mm})$ was put under one-line loading with rubber pieces to prevent the crushing of concrete's surface. A force was applied using a hydraulic jack Loading was controlled with software. The monotonically loading was applied with increased $(1 \mathrm{kN} / \mathrm{s})$ increments. The slab was loaded until failure occurred. The acting force and deflection of the specimens at the middle length of slab were measured during the test.

The cracks at ultimate load were recorded and noticeable during the test.

\subsection{Finite Element Numerical Investigations}

A finite element analysis has been carried out to analyze a solid and void slab with the same materials properties used in the experimental work. For the present study ANSYS Mechanical APDL 19.0 is being used.

The Element types using in FEM models in the ANSYS Mechanical APDL 19.0 are CPT215 for concrete, REINF264 for discrete reinforcing and SOLID185 for steel plate. Elements type (CPT215, SOLID185 and REINF264) within the ANSYS model are illustrated in Table 3.

Table 3. Elements types using in FEM models.

\begin{tabular}{|c|c|c|c|c|}
\hline Element Types & Description & & & \\
\hline \multirow{6}{*}{ REINF264 } & \multicolumn{4}{|l|}{ Linear Isotropic } \\
\hline & Ex & \multicolumn{3}{|l|}{200000} \\
\hline & PRXY & \multicolumn{3}{|l|}{0.30} \\
\hline & & & Yield Strength & Ultimate Strength \\
\hline & \multirow{2}{*}{ Bilinear } & Dia $10 \mathrm{~mm}$ & 535 & 697 \\
\hline & & Dia 6 mm & 305 & 460 \\
\hline \multirow{4}{*}{ CРT215 } & Linear Isotropic & $\mathrm{fck}=35.6 \mathrm{MPa}$ & & \\
\hline & Ex & 28043 & & \\
\hline & PRXY & 0.20 & & \\
\hline & Linear Isotropic & & & \\
\hline \multirow[t]{2}{*}{ SOLID185 } & Ex & 200000 & & \\
\hline & PRXY & 0.30 & & \\
\hline
\end{tabular}

\subsection{Modeling and Meshing}

In this study, the slabs were modeled as volumes. The concrete model that represent the slabs with and without longitudinal void tubes are formulated by drawing areas at plan (x-y) in the first step and subtract the cores areas and then extrudes them in (x-direction) to form the volume of the slabs as shown in Figure 4. In the present study, the net from longitudinal and transverse steel reinforcement bars which formed the reinforcement model was created through line element between nodes of each adjacent concrete solid element, so the two materials shared the same nodes. All the concrete CPT215 elements are meshed as rectangular brick element with $25 \mathrm{~mm}$ size. Meshing of the rebar element made same size of $25 \mathrm{~mm}$ as steel rebar is joined element between the spacing of the nodes created by the meshing of the concrete. In some regions especially in hollow block slabs, the size of element needs to be smaller than $25 \mathrm{~mm}$; this depends on the location and distribution of both the steel reinforcement and steel plate.

\subsection{Loads and Boundary Conditions}

The loading and support dimensions of steel plates were $(50 \times 300) \mathrm{mm}$. Two steel plates of $(20 \mathrm{~mm})$ thickness are modeled using (SOLID185) elements, were added at the support and one steel plate at loading locations with the same size of concrete mesh in order to avoid stress concentration problems. This will provide a more even stress distribution over the support area. The (SOLID185) elements which are used to model steel plates at supports have three degrees of freedom UX, UY and UZ. These degree of freedom at the bottom face of these plates are restrained with a single line of supports which placed under the centerline of the steel plate allow rotation of the plate 
below the concrete slab with the required positions as a simply support to simulate the real boundary conditions as shown in Figure 2 (e)\&(f).

The left steel plate was restrained in $\mathrm{Y}$ direction $(\mathrm{UY}=0)$ and the right steel plate was restrained in $\mathrm{X}$ and $\mathrm{Y}$ direction
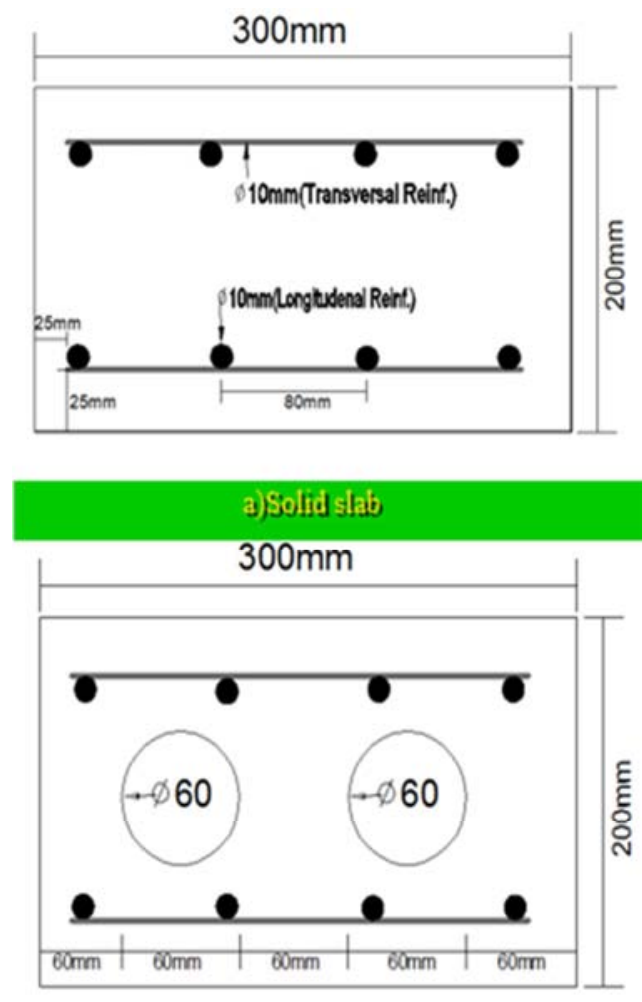

b) Woided-tube(60mm)
$(U X=0, U Y=0)$. The external loads were applied on one steel plate over the surface of concrete slabs with the required locations. These loads were applied in the form of concentrated loads on all top nodes of plates to simulate the real loads which adopted in the experimental work.
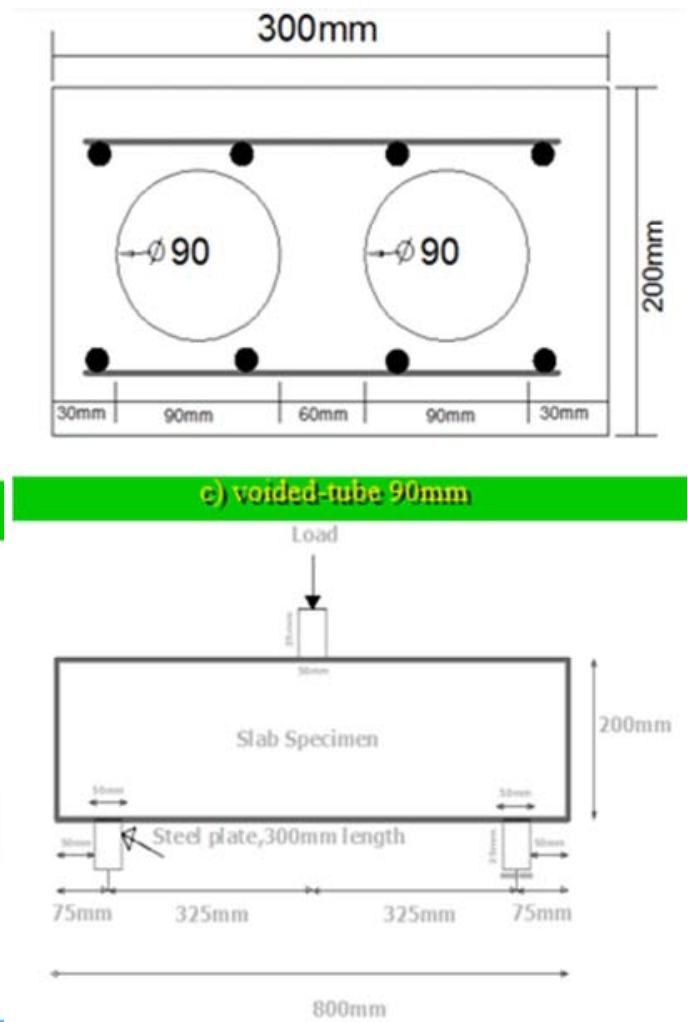

d) Test setup

Figure 1. Cross-sections of slab a) Solid slab (b) and (c) Voided-slab with tube diameter 60mm, 90mm and d) Test setup.

\section{Results and Discussions}

\subsection{Experimental and Numerical Results}

\subsubsection{Load-Deflection Behaviors of Slab}

The average load-deflection responses of the six slab test with and without void plots in Figure 3. The comparison presents between solid and longitudinal tubes voided slab with tubes diameter $60 \mathrm{~mm}$ and $90 \mathrm{~mm}$ by variation of voided tube diameter to slab thickness $(\mathrm{D} / \mathrm{H})$ ratio with ultimate load. The differences become more pronounced with progressing the loading as shown in Tables 4 and 5. At any load stage, the deflection value increases with increasing the diameter of tubes. In other words, as increasing void tubes diameter, the load deflection response of the slab becomes softer especially when $90 \mathrm{~mm}$ void tubes are used. Thus, increasing tubes diameter results in higher deflection value at failure made in the slab. The responses of the two slabs (SS200 and CPT60) failed by flexural mode. The load-deflection responses of slabs were much softer where a deflection considerably augmented with a marginal increase in the applied load. Similar responses were observed in the FEA studies.

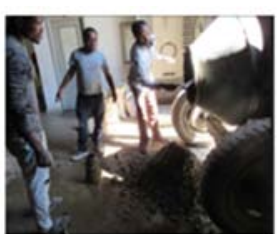

a)

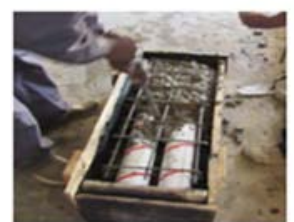

b)

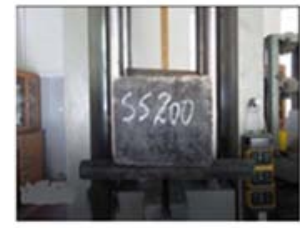

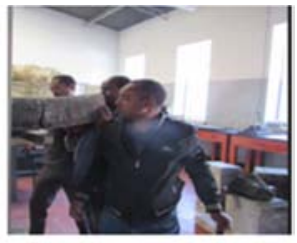

d)

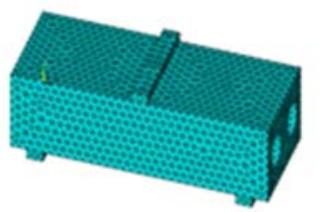

e)

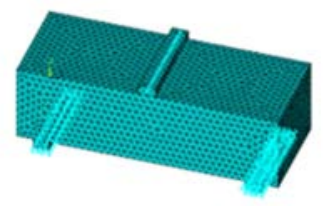

Figure 2. Preparation of the test specimen steps: (a) Concrete mixing process (b) Pouring and casting process (c) Specimen inside the testing frame (d) Specimen cracking result (e) Modeling and meshing (f) Loading and Restrained Condition of Slab. 
In general, introducing voided tubes inside slabs caused a reduced in the stiffness, and thus an increase in the deflection, compared to the SS200 slab at the same load level, as shown in Figure 3. The reduced in stiffness was slight before the yielding of tensile re-bars and became significant after that. Based on load-deflection curves the following points were noted:

The experiment result showed that the solid slab carried a load of $180.81 \mathrm{KN}$ and causes $36.87 \mathrm{~mm}$ deflection with crack occurring after a load of $74.85 \mathrm{KN}$. as shown in Table 4. Longitudinal voided slab with $\mathrm{D} / \mathrm{H}$ ratio of 0.30 carried a total load of $165.45 \mathrm{KN}$ and caused $39.80 \mathrm{~mm}$ deflection; with crack occurring after a load of $72.30 \mathrm{KN}$, the other longitudinal hollow slab with $\mathrm{D} / \mathrm{H}$ ratio of 0.45 carried a total load of $145.75 \mathrm{KN}$ and causes $41.30 \mathrm{~mm}$ deflection; with crack occurring after a load of $69.05 \mathrm{KN}$.

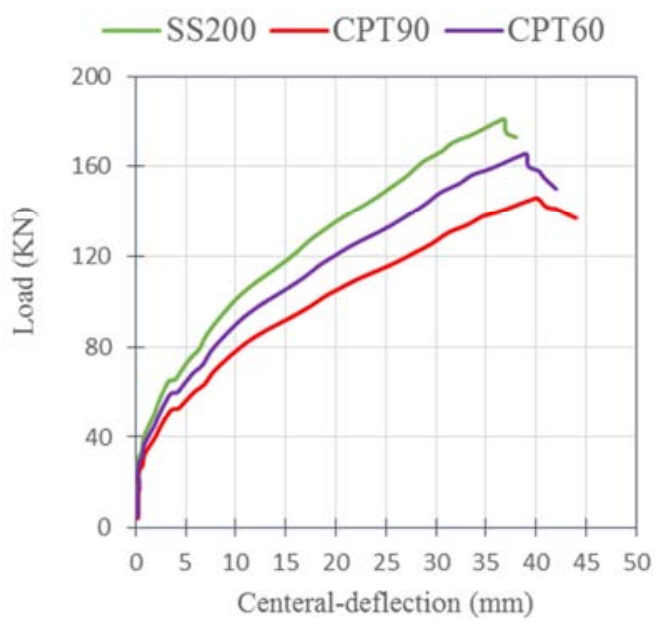

Figure 3. Load-deflection responses of average experiment slab specimen.

Table 4. Load-deflection of all experimental test slab results.

\begin{tabular}{|c|c|c|c|c|c|c|}
\hline \multirow{2}{*}{ Slab type } & \multirow{2}{*}{ Specimen codes } & \multirow{2}{*}{ D/H Ratio \% } & \multicolumn{2}{|c|}{ Load (kN) } & \multicolumn{2}{|c|}{ Deflection (mm) } \\
\hline & & & (Pcr) & $(\mathbf{P u})$ & $(\Delta \mathrm{cr})$ & $(\Delta \mathbf{u})$ \\
\hline \multirow{4}{*}{ Solid } & SS200-1 & None & 74.83 & 180.82 & 5.42 & 36.88 \\
\hline & SS200-2 & None & 74.87 & 180.80 & 5.40 & 36.86 \\
\hline & Average & None & 74.85 & 180.81 & 5.41 & 36.87 \\
\hline & СРТ60-1 & 30 & 72.00 & 165.90 & 6.70 & 39.80 \\
\hline \multirow[t]{2}{*}{ Voided-tube $(60 \mathrm{~mm})$} & СРТ60-2 & 30 & 72.60 & 165.00 & 6.72 & 39.80 \\
\hline & Average & 30 & 72.30 & 165.45 & 6.71 & 39.80 \\
\hline \multirow{3}{*}{ Voided-tube (90mm) } & СРТ90-1 & 45 & 69.09 & 145.08 & 8.12 & 41.55 \\
\hline & СРТ90-2 & 45 & 69.00 & 145.67 & 8.14 & 41.05 \\
\hline & Average & 45 & 69.05 & 145.75 & 8.13 & 41.30 \\
\hline
\end{tabular}

\subsubsection{Crack Pattern and Failure Mode}

All samples except the CPT90 slab failed in the flexural mode. The CPT90 collapsed owing to the shear mode. The study revealed that introducing tubes with a diameter equivalent to $45 \%$ of the slab depth led to changing the failure mode from flexural to shear, although the slabs were designed to fail in flexure. Besides, no concrete crushing was visible on the top surface of the CPT90 slab. The main reason for the collapse was developing diagonal (shear) cracks over the shear span, as shown in Figure 4.

For specimens failed in flexure, more vertical cracks grew and spread over the flexural span with increasing the applied loads. Then with further load, these cracks enlarged and propagated upward. The flexure-shear cracks also appeared in the shear span next to the loading points in the CPT60 specimen. Nevertheless, these cracks did not propagate and widen enough to cause failure. In these slabs, the flexural failure was distinguished by the arrival of flexural cracks nearly to the bottom two-third of the specimen depth as well as the crushing of concrete on the top surface of specimens at the mid-span. As expected, the longitudinal voided slab specimens cracked at forces lower than that of the control slab because of the direct reduction in their moment of inertia due to eliminating the substantial volume of concrete by voids. The decreased in the cracking load become more as the size of tubes increased, as shown in Tables 4 and 5.

Figure 4 shows the location of cracks from experimental test and finite element analysis along the solid and voidedtube slabs with tubes diameter $(60 \mathrm{~mm}$ and $90 \mathrm{~mm})$ respectively.

\subsubsection{Ultimate Strength and Weight Reduction}

Table 4 lists the ultimate loads for all slabs in experimental work, and Figure 5 plots them against $(\mathrm{D} / \mathrm{H})$ ratio. Inserting the longitudinal voided diameter of $60 \mathrm{~mm}(30 \%$ of slab thickness) in CPT60 slab caused an apparent drop about $8.50 \%-12 \%$ in the ultimate strength compared to the control slab. The cavity results in the reduction in the minimum load capacity when compared to the load capacity of the solid slab.

For the CPT90 specimen, containing the larger void-tube diameter ( $45 \%$ of slab thickness), the fall in the ultimate load was the maximum, about $19.40 \%-20 \%$. This reduced in the strength would be allocated to the growth of the diagonal cracks, spreading between loading and supporting locations. These cracks made the CPT90 slab early collapsed in the sudden brittle shear mode owing to reducing the critical section of concrete, which is responsible for resisting the high shear stresses produced in the shear span. Compared to the previous study by Abed in (2016) the decline in strength for CPT90 was similar with that of reported by Abed in (2016) for slab having voids with $(\mathrm{D} / \mathrm{H})$ of $60 \%$, which was $20.60 \%$.

The reductions in the self-weight of specimens CPT60 and CPT90 were $9.42 \%$, and $21.20 \%$, respectively, in comparison with the SS200 slab which is an added advantage for the 
longitudinal voided slabs especially in structures where load is an issue.

Table 5. Load-deflection of FEA slab results.

\begin{tabular}{llllll}
\hline $\begin{array}{l}\text { Specimen } \\
\text { codes }\end{array}$ & $\begin{array}{l}\text { D/H } \\
\text { Ratio } \%\end{array}$ & \multicolumn{2}{l}{ Load $(\mathbf{k N})$} & \multicolumn{3}{c}{ Deflection $(\mathbf{m m})$} \\
\cline { 3 - 6 } SS200 & $\ldots$. & 81.53 & $\mathbf{P u})$ & $(\Delta \mathbf{c r})$ & $(\Delta \mathbf{u})$ \\
CPT60 & 30 & 75.75 & 173.36 & 5.01 & 34.14 \\
CPT90 & 45 & 65.23 & 157.60 & 7.26 & 36.19 \\
\hline
\end{tabular}

It is noted that increasing void tube diameter causes reduction in weight and ultimate capacities. Using $90 \mathrm{~mm}$ diameter voids have significant effect on reducing weight and ultimate capacities in comparison with $60 \mathrm{~mm}$ diameter voids. Effect of hollows diameter on reduction in weight is significantly larger than its effect on ultimate capacity. These differences become more pronounced with increasing the diameter of voids.

Generally, the reductions in the ultimate load strength of voided slab are acceptable, compared with a significant drop in their self-weight, where the self-weight in concrete structures comprises a considerable part of the design loading.
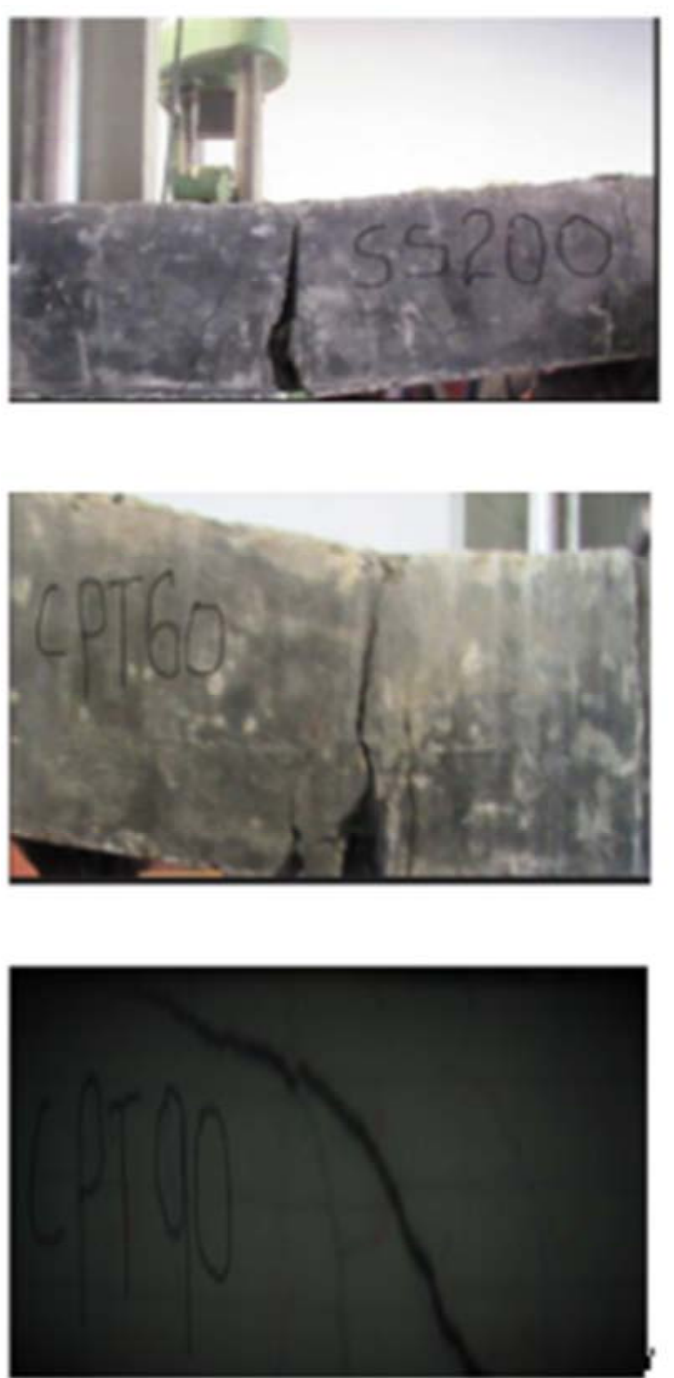

Figure 4. Cracks pattern of all slabs at collapse from experimental and FEA results.
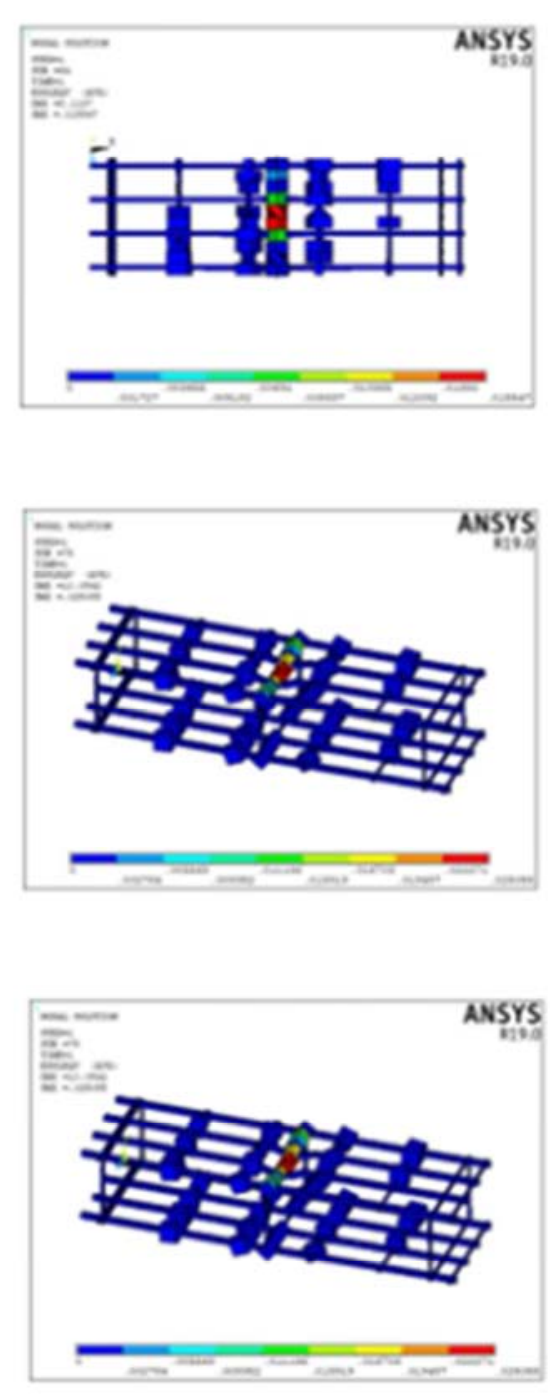

The selection of optimum voided tubes diameter presents by comparison with reduction of weight and reduction of strength. The curves are intersecting in optimum core diameter $(60 \mathrm{~mm})$ in which the reduction in weight nearly equals the reduction in strength and small lost in the ultimate strength was observed as well as the drops in the stiffness, ductility, and toughness of slab were limited.

\subsubsection{Comparison of Experiments vs FEA}

The comparative study is made between the experimental results with finite element analysis results. The load versus deflection plots obtained from the experimental and the numerical study are presented for comparison in this section. Figure 6 (a)\&(b) compares the numerical and experimental load deflection relationship for both the slabs with and without void.

A comparison between the ultimate loads of the experimentally tested slabs $(\mathrm{Pu})_{\operatorname{Exp}}$ at failure stage and the final loads obtained from finite element analysis $(\mathrm{Pu})_{\text {FEM }}$ is analyzed. 


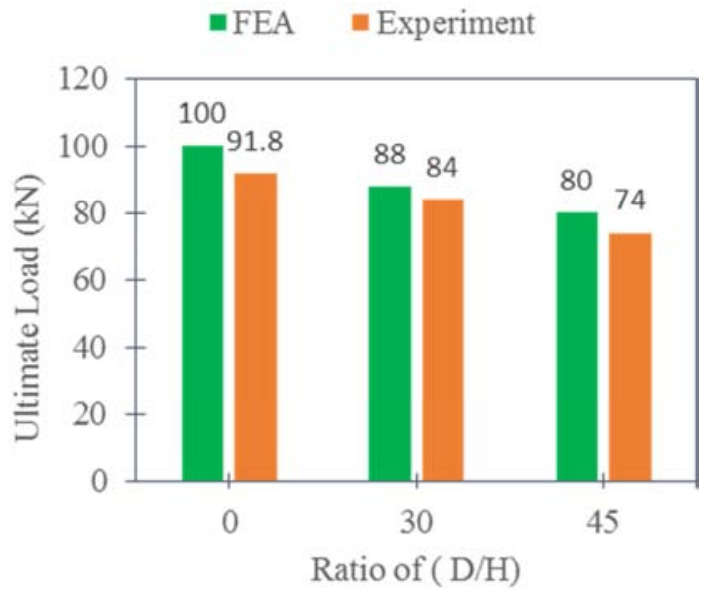

Figure 5. (D/H) Ratio versus Ultimate strength.

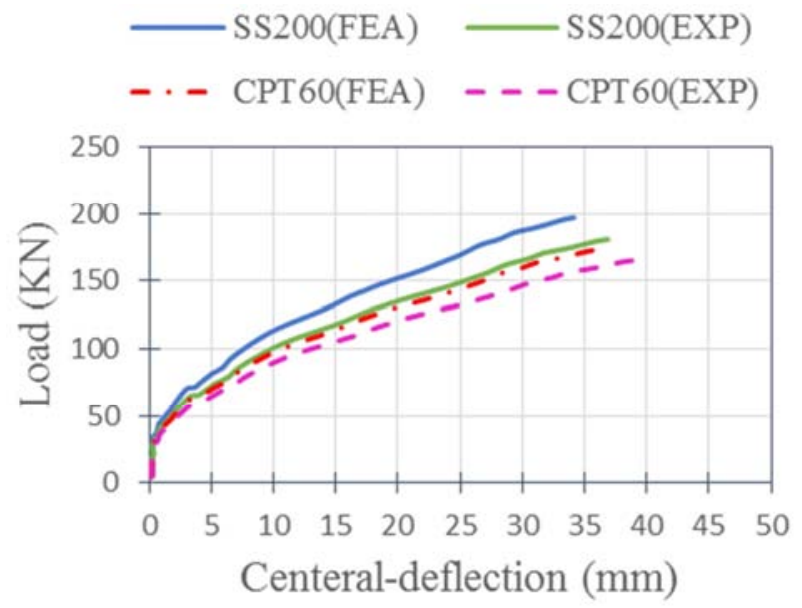

a)

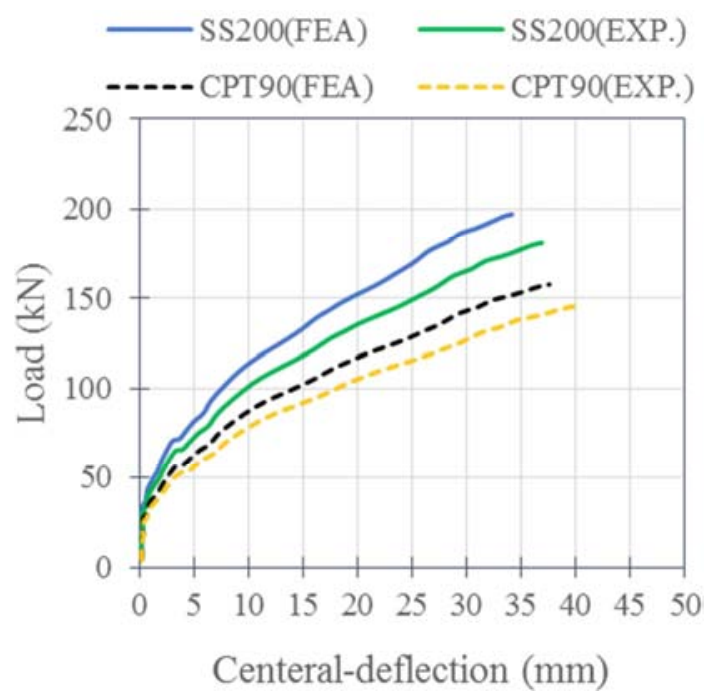

b)

Figure 6. (a) \&(b) Comparison of load-deflection response of Experimental and FEM results.

The numerical investigations indicated that smaller deflection with greater ultimate load as compared to experimental results. Those errors (between experimental and finite element results) are essentially introduced by representing the mathematical model by a finite-element one. The FEA solution is influenced by the number of elements used, the nature of element shape functions, support conditions and loading type integration rules used in details of particular elements.

\subsubsection{Flexural Stiffness, Ductility and Toughness}

i) Flexural Stiffness

The stiffness is one of the basic parameters in evaluating the working ability of the structural element. Various definitions for stiffness are found in the literature. Among them, the flexural stiffness can be expressed as the force (Py) required divided by the corresponding deflection $(\Delta y)$ of one unit. Based on the load-deflection graph, all slab specimens yield before collapse at a load in a range of $65.23 \mathrm{kN}$ $81.53 \mathrm{kN}$, as stated in Table 6 .

In comparison with the solid slab (SS200), the voided slabs gave smaller flexural stiffness about $22.18 \%-25.0 \%$ and $38.66 \%-38.80 \%$ for slab having $60 \mathrm{~mm}$ and $90 \mathrm{~mm}$ void diameter respectively. This reduction in the flexural stiffness of voided slabs could be attributed to following reasons:(1) the direct reduction in the moment of inertia of voided slabs due to existing tube voids; (2) the presence of voids made growth and enlargement of cracks notably fast; and (3) placing the voids directly above the tensile steel reinforcement resulted in removing an amount of concrete surrounding these steel reinforcement, and hence the bond strength decreased.

ii) Ductility Ratio

Ductility is a measurement, discussing the capability of a structural member to show a significant inelastic deformation prior to collapse. The reinforced concrete members should be designed with an acceptable ductility to ensure an adequate warning before failure to save residents as well as their properties. Therefore, evaluating the influence of voids on the ductility of slabs is necessary. The ductility was calculated as a ratio of $(\Delta \mathrm{u} / \Delta \mathrm{y})$. Where $\Delta \mathrm{y}$ and $\Delta \mathrm{u}$ are the displacements at the yield point and ultimate loads, respectively. The results are stated in Table 6 with respect to void size to slab thickness ratio $(\mathrm{D} / \mathrm{H})$.

The presence of voids inside the area of one-way slabs caused a drop in the ductility value. Although the CPT60 slab, having voids with a diameter equal to $30 \%$ of slab depth, failed in the flexural mode as the solid slab, it lost about $13 \%$ $-14.64 \%$ of their ductility compared with the reference solid slab. For slab with the larger tube (CPT90, D/H=45\%), the decrease in the ductility value was most significant, reaching about $24.30 \%-25.50 \%$, since this slab experienced a brittle shear failure. Thus, for longitudinal voided slabs constructed in regions seismic zone needs special consideration. 
Table 6. Effect of D/H ratio on stiffness, ductility and toughness.

\begin{tabular}{llllllll}
\hline \multirow{2}{*}{ Slab } & \multirow{2}{*}{ D/H Ratio } & \multicolumn{2}{c}{ Stiffness $(\mathbf{k N} / \mathbf{m m})$} & \multicolumn{2}{c}{ Ductility Ratio } & \multicolumn{2}{c}{ Toughness (kN-mm) } \\
\cline { 3 - 8 } & & EXP & FEA & EXP & FEA & EXP & FEA \\
\hline SS200 & --- & 13.84 & 16.27 & 6.82 & 6.81 & 4460 & 4483 \\
CPT60 & $30 \%$ & 8.46 & 11.09 & 5.82 & 5.83 & 4313 & 4182 \\
CPT90 & $45 \%$ & 7.01 & 9.00 & 5.08 & 5.17 & 3395 & 3945 \\
\hline
\end{tabular}

iii) Toughness

The capacity of RC members to absorb energy before revealing a notable drop in the load carrying strength is called toughness. The toughness is a very basic criterion for reinforced concrete members susceptible to impact load or seismic load. Thus, assessing the effect of voids on the toughness of slabs is very important. The toughness is measured as the area below the load-deflection plot of a member up to failure load. Table 6 shows the toughness values of the three slabs.

The results showed that inserting of a longitudinal void inside the slabs causes in reducing energy absorption capacity in comparison with the control solid slab. In reinforced concrete members, the energy absorption depends mainly on the ability of concrete to resist fracture and cracking. The loss of an extensive amount of concrete in the voided slabs led to reducing their toughness.

In comparison with the solid slab, the drop in the toughness was approximately $3.30 \%-6.71 \%$ when the voids with a diameter of $30 \%$ of the slab thickness were employed as in slab CPT60. This percentage rose to $10.43 \%-12.00 \%$ due to enlarging the diameter of the voids to $45 \%$ of the slab depth (CPT90). As the literature shows, the slabs with the biggest void's ratio $(\mathrm{D} / \mathrm{H})$, the ability to absorb energy remarkably dropped and owing to the collapse of the slab in the shear mode without displaying an excessive deflection.

\subsection{Additional Parametric Study Using FEA}

Additional parametric study was then carried out to identify the effects of compressive strength of concrete, loading types and top layer of reinforcement on the behavior of the longitudinal voided reinforced concrete slabs. The reinforced concrete voided slab having circular tube diameter $90 \mathrm{~mm}$ under $(D / H)$ equal $45 \%$ was selected to study the influence of additional parametric using ANSYS computer software.

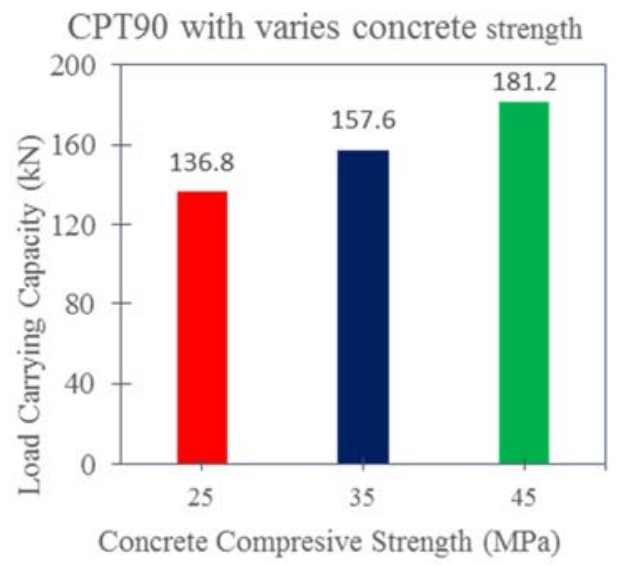

Figure 7. Effect of compressive strength of concrete.

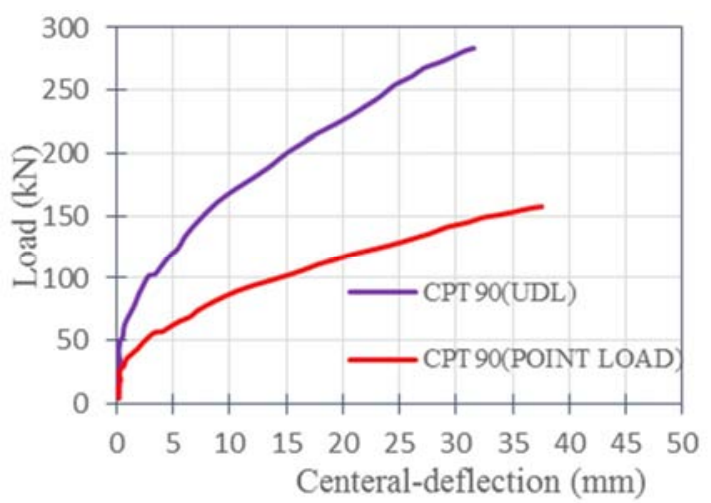

Figure 8. Effect of loading type.

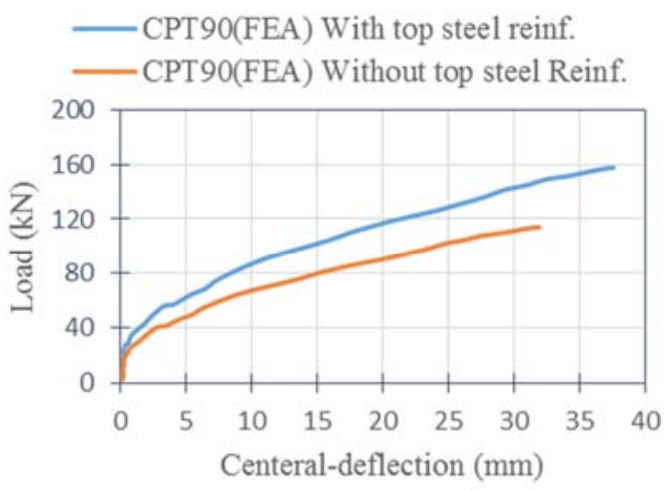

Figure 9. Effect of top layer of reinforcement.

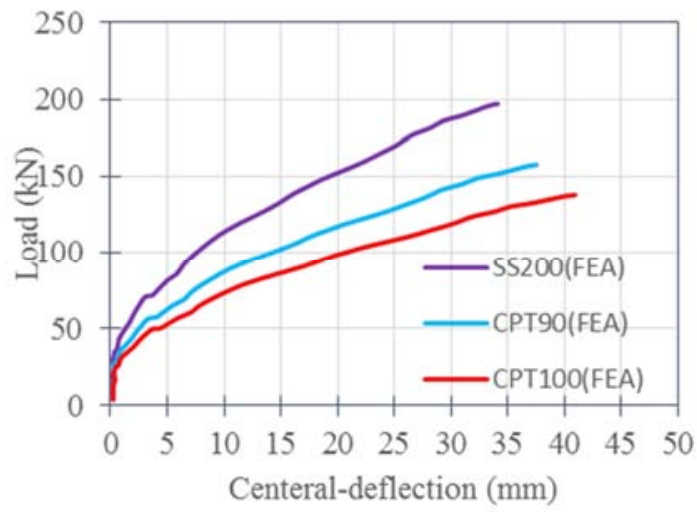

Figure 10. Load-Deflection of slabs SS200, CPT90 and CPT100.

\subsubsection{Effect of Compressive Strength of Concrete}

It has been found that using different values of concrete compressive strength as $(25,35.6$ and 45) MPa respectively on the behavior of load deflection plot. The Figure 7 showed that the response of the considered R. C void tube slab for different concrete compressive strength. When the concrete strength increases from (35.6MPa) to (45MPa), the ultimate strength increases by $15.50 \%$ as well as greater ductility and when the compressive strength decreases from (35.6MPa) to 
(25MPa), the ultimate strength reduces to about $12.78 \%$.

\subsubsection{Effect OF Loading Type}

The results indicate that the ultimate total load of this slab was increased from $157.57 \mathrm{kN}$ for single point load to $283.63 \mathrm{kN}$ about $80 \%$ under uniform load type with decreasing in deflection by about $16 \%$ as shown in Figure 8.

It can be seen from the Figure 8 the polyline appeared clearly in load- deflection curve for load values between $56.97 \mathrm{kN}$ and $102.55 \mathrm{kN}$ which refers to the transformation stage of numerical solution from linear to non-linear behavior at the point of cracking occurs.

\subsubsection{Effect of Top Layer of Reinforcement}

Figure 9 displays the effect of using top steel reinforcement with bottom one. The longitudinal voided slab with tube diameter $90 \mathrm{~mm}$ under single point loading with $(\mathrm{D} / \mathrm{H})$ equal $45 \%$ was analyzed first with bottom and top reinforcement as presented before then analyzing the same slab with removing the top reinforcement. It was noted that the ultimate load capacity of the slab will be decreased by about $15 \%$ with removing the top reinforcement. This is may be due to the existence of top reinforcement will distribute the stresses around the tube and prevent crushing.

\subsubsection{Effect of Size of Circular Tubes}

The longitudinal voided slabs having circular tube shapes with additional tube diameter of $100 \mathrm{~mm}$ was analyzed under same loading and support conditions. The analysis results of load-deflection curves and comparison with sizes of hollow cores were presented at Figure 10. Based on analysis result, it was noted that increasing void sizes leads to reduction in cracking and ultimate capacities. Using $100 \mathrm{~mm}$ diameter size of tube has significant effect on reducing cracking and ultimate capacity in comparison with using $90 \mathrm{~mm}$ diameter tubes for all loading stages. Increasing circular tubes diameter results in higher deflection by $9 \%$ and reduce the ultimate load by $12 \%$ at failure.

\subsection{The Proposed Theoretical Calculation of Slab Capacity Based on ACI318-19 and EC2 Codes}

\subsubsection{Computation of Ultimate Moment Capacity}

The flexural strengths of slabs have been calculated based on EC-2 and ACI 318M-19 codes. The flexural stress across the slab thickness at the ultimate load for both codes are showed in Figure 11. In the voided slabs, there are two possible shapes for the compression zone, depending on the compression depth (a).

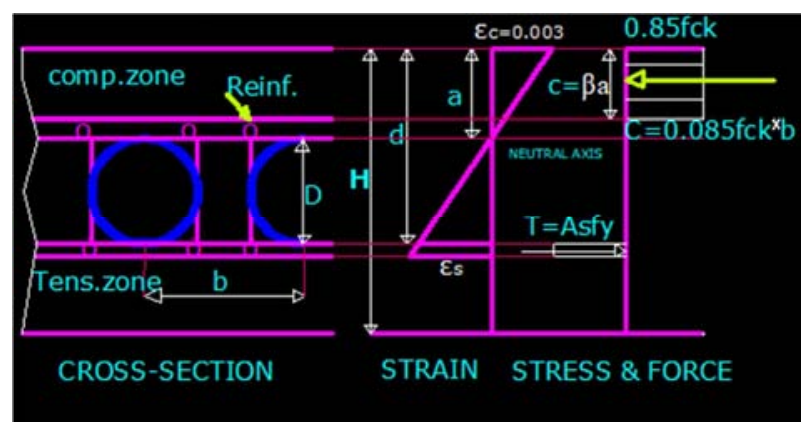

Figure 11. Distribution of stress-strain across the slab depth.

If the compression depth does not enter the voids zone, the compression zone is rectangular, and the ultimate moment is determined as in the case of the solid slab (i.e. no reduction in bending moment capacity). Otherwise, the compression zone is irregular and lengthy calculations are needed for computing the area and center of the compression location. In this study, the forces of the voided slabs are almost equivalent to that of the solid slabs since the compression depth of all slabs was located above the longitudinal voided tubes and the compression zone is considered as rectangular. The depth of compression zone (a) is evaluated based on equilibrium condition, assuming that the failure will be initiated by yielding of the tensile reinforcement steel ( $\mathrm{fs}=\mathrm{fy}$ ) for an under reinforced section.

The stress distribution block in concrete gives the exact behavior of slab's ultimate strength so that the capacity of the section can be calculated using the following equations.

$$
\mathrm{M}_{\mathrm{u}}=\mathrm{A}_{\mathrm{st}} \mathrm{f}_{\mathrm{y}}(\mathrm{d}-\mathrm{a} / 2)
$$

Where the depth of compression zone (a) is given by

$$
\mathrm{a}=\mathrm{A}_{\mathrm{st}} * \mathrm{f}_{\mathrm{y}}\left(\mathrm{f}_{\mathrm{y}} /\left(\eta \mathrm{b} * \mathrm{f}_{\mathrm{c}}\right)\right)
$$

Where $\eta$ is a factor to convert the irregular shape of the concrete stress into the rectangular shape, $b$ is width of slab crosssection, $A_{s t}$ area of steel reinforcement, $\beta$ ', defining the effective height of the compression zone $\& d$ is the effective depth.

\subsubsection{The Proposed Method for Calculating the Ultimate Load for Slab}

The proposed method to find an ultimate load for simply supported slab has been predicted by using ultimate load versus displacement graph of experimental, and matching the values with calculated ultimate load strength. Besides, further investigation has been done by means of using different equations and expressions based on the geometry of the load to compute the ultimate load carrying capacity $(\mathrm{Pu})$ of the section.

Table 7. Ratio of Experimental and Calculated Ultimate Loads of Slabs using ACI318M-19 and EC2 codes and also Numerical loads.

\begin{tabular}{lllllll}
\hline \multirow{2}{*}{ Slab specimens } & \multirow{2}{*}{ Pu Exp (kN) } & ACI318M-19 & & EC2 & FEA \\
\cline { 3 - 6 } & & Pu & Pu/Pu Exp & Pu & Pu/Pu Exp & Pu \\
\hline SS200 & 180.81 & 134.78 & 0.75 & 136.5 & 0.76 & 196.96 \\
CPT60 & 165.45 & 134.78 & 0.82 & 136.5 & 0.83 & 173.30 \\
CPT90 & 145.75 & 134.78 & 0.93 & 136.5 & 0.94 & 1.09 \\
& Mean & 0.833 & & 0.843 & 1.05 & 1.073 \\
& DC & 0.072 & & 0.074 & 0.017 \\
& CV & 0.090 & 0.090 & & 0.016 \\
\hline
\end{tabular}




\section{Conclusions and Recommendations}

\subsection{Conclusions}

Based on the analysis results of the experimental work, nonlinear finite element numerical investigation and theoretical calculations of both solid and longitudinally void slabs can be summarized as stated below:

1. The deflection and load response are significantly influenced by presence of voids. This response is softer with increasing voids size and leads to larger displacement at failure.

2. All specimens except the CPT90 slab failed in the flexural mode. The CPT90 collapsed owing to the brittle shear mode. For specimens failed in flexure, more vertical cracks grew and spread over the flexural span with increasing the applied loads and for specimens failed in shear the collapse was developing diagonal cracks over the shear span.

3. Reducing the self-weight of the moderate thick reinforced concrete slabs by about $21.20 \%$ with longitudinal void tubes (diameter $=90 \mathrm{~mm}$ ) lead to reduce the ultimate strength by about $19.40 \%-20 \%$ while reducing the weight by about $9.42 \%$ with void tubes (diameter $=60 \mathrm{~mm}$ ) lead to reduce the ultimate strength by about $8.50 \%-12 \%$. At the same time increase in deflection by $6 \%$ to $10 \%$ was noticed with $60 \mathrm{~mm}$ and $90 \mathrm{~mm}$ voided slabs respectively.

4. The comparison result between finite element and experimental results showed that the difference range was $8 \%-8.50 \%$ in ultimate load and $7 \%-8.20 \%$ in deflection. The numerical results showed that smaller deflection with larger ultimate load as compared to experimentally results.

5. In comparison with the solid slab (SS200), the voided slabs gave smaller flexural stiffness and about $22.18 \%$ $25.50 \%$ for slab having $60 \mathrm{~mm}$-tubes; this percentage increased to $38.66 \%-38.80 \%$ for slabs containing larger voids size $90 \mathrm{~mm}$.

6. The presence of voids inside the area of one-way slabs caused a drop in the ductility value. The CPT60 slab, having voids with a diameter equal to $30 \%$ of slab depth, it lost about $13 \%-14.64 \%$ of their ductility compared with the reference solid slab. For slab with the larger tube (CPT90, D/H=45\%), the decrease in the ductility value was most significant, reaching about $24.30 \%-25.50 \%$, and this slab experienced a brittle shear failure.

7. The results stated that the presence of voids inside slabs resulted in less energy absorption (less in toughness) in comparison with the solid slab. The reduction was $3.30 \%-6.71 \%$ when the size of the tubes was less than $30 \%$ of the slab thickness. For the CPT90 slab, the absorbed energy decreased about $10.43 \%-12 \%$.

8. Using high concrete strength leads to improvements in mechanical properties of concrete that increase cracking capacity and slab stiffness in addition to reducing crack width with small change in deflection value. This constructive action substitutes the undesirable action for using voids on these values. Thus, high strength concrete grade is very useful in voided slabs.

9. When the compressive strength of the concrete increases from $(35.6 \mathrm{MPa})$ to $(45 \mathrm{MPa})$, the ultimate strength increases by $15.50 \%$ and when the compressive strength decreases from $(35.6 \mathrm{MPa})$ to $(25 \mathrm{MPa})$, the ultimate strength reduces to about $12.76 \%$.

10. It was found that the ultimate strength of the voids slab increases by about $80.05 \%$ for the case of uniform load and a reduction in deflection by $16.02 \%$ compared to one point load with $(\mathrm{D} / \mathrm{H})$ equal $45 \%$.

11. By removing the top steel reinforcement in void slab declined the ultimate strength by about $15 \%$ due to crushing failure of top flange of concrete so that it is recommended to use this layer to prevent this failure.

12. Increasing diameter of tubes causes reductions in cracking and ultimate capacities with increasing the deflections. Increasing circular tubes diameter from $90 \mathrm{~mm}$ to $100 \mathrm{~mm}$ results in higher deflection by $9 \%$ and reduce the ultimate load by $12 \%$ at failure.

13. The EC2 and ACI 318M-19 codes have almost similar values in predicting the flexural strength of slabs and good agreement with the experimental result.

\subsection{Recommendations}

1. From a practical point of view, the use of tubes with a size equal to $30 \%$ of the slab thickness is recommended since small lost in the ultimate strength was observed as well as the drops in the stiffness, ductility, and toughness of slab were limited as compared with solid slab.

2. It is also recommended that the optimum core diameter in hollow-core slab is $(60 \mathrm{~mm})$ because of that the failure modes and crack types are similar with that of the control solid slab, in addition the reduction in weight is larger than reduction in strength.

3. Using high concrete strength leads to improvements in mechanical properties of concrete that increase cracking capacity and slab stiffness in addition to reducing crack width and deflection. This constructive action substitutes the negative action for using voids on these values. A very good example of this would be the SS200 with C-35MPa and CPT90 with C-45MPa have the same ultimate strength. Therefore, high strength of concrete grade is very useful in voided slabs.

4. The analysis results compared with the results of the same slab under single point loads with the ratio $(\mathrm{D} / \mathrm{H}=45 \%)$ and under uniform load. The results indicate that the ultimate total load of voided slab was increased significantly under uniform load type with decreasing in deflection. Therefor using voided slabs in the area where uniformly distributed loads applied is 
more preferable than concentrated point loads.

\section{Acknowledgements}

First and foremost, I would like to thank my Advisor Dr. Tesfaye Alemu, for all the help and guidance he provided me. My hearty gratitude is also extended to Dr. Temesgen Wondimu for his support in major courses to do this paper.

I am very grateful to ERA in collaboration with AASTU for providing me MSc. study.

I am indebted to many of my friends, family and to all individuals who have contributed directly or indirectly for providing a stimulating environment throughout in writing this thesis.

\section{References}

[1] Yang L. 1994. Design of Pre-Stressed Hollow Core Slabs with Reference to Web Shear Failure. Journal of Structural Engineering, ASCE. 120 (9): 2675-2696.

[2] Pajari Matti. 2004. Pure Torsion Tests on Single Hollow Core Slabs. Espoo VTT Tiedotteita, Research Notes 2273, pp. 2928.

[3] Mahdi A. S. 2011. Nonlinear Finite Element Analysis of Reinforced Concrete Hollow-core Slabs. MSc. Thesis, AlNahrain University/Civil Engineering Department.

[4] Rahman M. K., M. H. Baluch, M. K. Said, M. A. Shazali. 2012. Flexural and Shear Strength of Pre-Stressed Precast Hollow-Core Slabs. Arabian Journal for Science and Engineering. 37 (2): 443-455.

[5] Haruna S. I. 2014, "Flexural behavior of precast pre-stressed concrete hollow core slabs with cast-in-place concrete topping”, M. S. Dissertation, Atılım University, Turkey.
[6] Lee, D. H., Park, M., Oh, J., Kim, K. S., Im, J. and Seo, S. (2014), "Web-shear capacity of pre-Stressed hollow core slab unit with consideration on the minimum shear reinforcement requirement", Comput. Concrete, 14 (3), 211-231.

[7] Ibrahim I. S., K. S. Elliott, b., Abdullah, R., Kueh A. B. H., Sarbini N. N. 2016. Experimental Study on the Shear Behavior of Precast Concrete Hollow Core Slabs with Concrete Topping. Engineering Structures. 125: 80-90.

[8] Abed S. A. 2016. Flexural Behavior of One Way Reinforced Concrete Hollow- Core Slabs under Monotonic Loading. MSc. Thesis, Al-Nahrain University/Civil Engineering Department.

[9] Foubert S., Mahmoud K. and El-Salakawy E. 2016. Behavior of Pre-Stressed Hollow-Core Slabs Strengthened in Flexure with Near-Surface Mounted Carbon Fiber-. Reinforced Polymer Reinforcement. ASCE, Journal of Composites for Construction. 20 (6).

[10] Wariyatno N. G., and Haryanto Y. and Sudiboyo G. H. 2017. Flexural behavior of precast hollow core slab using PVC pipe and Styrofoam with different reinforcement. Procedia engineering. 171: 909-916.

[11] ACI318-14.2014. Building Code Requirements for Structural Concrete (ACI 318-14) and Commentary. American Concrete Institute, Detroit, U.S.A.

[12] EN 1992-1-1, Eurocode 2: Design of Concrete Structures Part 1-1-General Rules and Rules for Buildings, London Br. Stand. Inst., 2004.

[13] ANSYS19.0 Inc. 2019. ANSYS User's Manual. SAS IP, Inc., Version 19.0, U.S.A.

[14] Mansour F. R., Abu BakarS., Ibrahim, I. S., MarsonoA. Marabi B. 2015. Flexural performance of a precast concrete slab with steel fiber concrete topping. Construction and Building Materials. 75: 112120.

[15] PCI Manual for the Design of Hollow Core Slabs and Walls Third Edition - Electronic Version. 